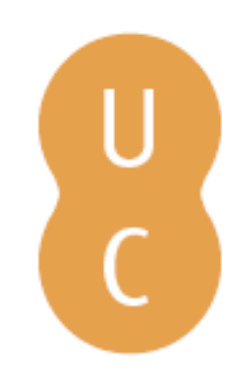

\title{
nombalina
}

\section{Soluções mágicas ou realidade?}
Autor(es): $\quad$ Cordo, Margarida
Publicado por: Imprensa da Universidade de Coimbra
URL
persistente:
URI:http://hdl.handle.net/10316.2/35966
DOI:
DOI:http://dx.doi.org/10.14195/978-989-26-0852-5_13

Accessed : $\quad$ 26-Apr-2023 14:12:31

A navegação consulta e descarregamento dos títulos inseridos nas Bibliotecas Digitais UC Digitalis, UC Pombalina e UC Impactum, pressupõem a aceitação plena e sem reservas dos Termos e Condições de Uso destas Bibliotecas Digitais, disponíveis em https://digitalis.uc.pt/pt-pt/termos.

Conforme exposto nos referidos Termos e Condições de Uso, o descarregamento de títulos de acesso restrito requer uma licença válida de autorização devendo o utilizador aceder ao(s) documento(s) a partir de um endereço de IP da instituição detentora da supramencionada licença.

Ao utilizador é apenas permitido o descarregamento para uso pessoal, pelo que o emprego do(s) título(s) descarregado(s) para outro fim, designadamente comercial, carece de autorização do respetivo autor ou editor da obra.

Na medida em que todas as obras da UC Digitalis se encontram protegidas pelo Código do Direito de Autor e Direitos Conexos e demais legislação aplicável, toda a cópia, parcial ou total, deste documento, nos casos em que é legalmente admitida, deverá conter ou fazer-se acompanhar por este aviso. 



\section{S OLUÇÕ ES MÁGICAS OU REALIDADE?}

\section{Introdução}

Antes de iniciar esta intervenção gostaria de agradecer o convite que me foi dirigido para participar no II Congresso de Reabilitação e Inclusão na Saúde Mental e dizer que é com muito gosto que aqui estou mais uma vez, procurando dar um contributo para a reflexão e para uma boa discussão em matérias tão sensíveis como é esta de reduzir a dependência e promover a autonomia de pessoas com doença mental.

Há já algum tempo confrontei-me com a leitura de um livro que recomendo vivamente - O Solista - e que hoje está nos cinemas sob a forma de longa-metragem que também sugiro que seja vista, pois, não dispensando a leitura da história que a inspirou, fornece uma imagem forte e muito real do que nela é descrito.

$\mathrm{Na}$ realidade, todos conhecemos situações de sofrimento que sabemos serem evitáveis e que resultam do facto de as pessoas que adoeceram com patologia psiquiátrica não estarem em tratamento nem terem qualquer ajuda. Não se trata de uma doença como as outras em alguns aspectos, se assim se pode dizer, nem de liberdade para consentir de um modo informado e esclarecido, pois, frequentemente, na doença mental a vontade também está “doente”. Os sintomas produtivos, quando existem,

\footnotetext{
${ }^{1}$ Coordenadora dos Serviços de Reabilitação da Casa de Saúde do Telhal; Membro do Conselho de Administração da Fundação S. João de Deus; Directora Técnica da Conforsaumen Serviços Privados de Psicologia, Psicoterapia e Promoção do Bem-Estar Integral para Doentes e Famílias; Docente de Instituições de Ensino Superior. E-mail: margarida.cordo@ isjd.pt; m.cordo@conforsaumen.com.pt
} 
são verdadeiramente avassaladores e os negativos impeditivos de uma iniciativa, de um contacto, de um gesto de proximidade e de um poder dizer sim ou não que seja conveniente e proveitoso para quem o diz ou não chega a ser capaz de o dizer.

Nathaniel, O Solista, era um sem-abrigo com doença mental e genial na interpretação musical. Um jornalista, autor do livro, tornou-se seu amigo e quis ajudá-lo, mas ele não queria ajuda. Preferia a rua, a liberdade, a protecção dos desprotegidos que, aparentemente, não temia, mas dos quais tendia a afastar-se...

Isto é apenas uma síntese, pois nesta obra somos também confrontados, entre outros conteúdos, com instituições para pessoas com doença mental que "respeitam" o facto de elas não tomarem/não quererem tomar medicação.

Não cabe nesta intervenção ir mais adiante no que poderia ser uma polémica, mas não posso deixar de dizer que, em minha opinião, este respeito pela liberdade do outro é um atentado à sua dignidade. É que, algumas doenças mentais graves têm como ponto de partida essencial a toma medicamente acompanhada e bem gerida de psicofármacos, o que faz toda a diferença e, por vezes, favorece o acesso ao mundo e à vida que fica bloqueado se os doentes estiverem "a descoberto". ${ }^{2}$

Esta referência com a qual vos quero despertar para os momentos de reflexão e de partilha que se seguem tem como objectivo maior sensibilizar para o facto de que a diferença não deve ser promotora de um estigma que rejeita, que exclui e que abandona. As pessoas com doença mental, por mais difíceis e perturbadoras que se tornem para as vidas dos que as rodeiam, essencialmente os seus familiares, não podem ser alvo apenas de caminhos pré-fabricados, que definem com exactidão o que vão fazer agora e em cada “a seguir", como se fossem uma espécie de máquina importadora de cuidados prestados.

2 Terminologia utilizada para referenciar que a pessoa não está a tomar qualquer medicamento. 


\section{Haverá Soluções Mágicas?}

Quando estudamos os documentos que se vão estruturando à volta do que deve ser feito a nível da saúde mental no nosso país, percebemos uma séria evolução que conduzirá, decerto, à existência de respostas melhores e mais completas. A legislação aperfeiçoa-se; as alternativas consistentes e inovadoras vão sendo concebidas e, espera-se que, com o passar do tempo, postas em prática, para poderem ser utilizadas por quem delas beneficie.

Simultaneamente têm sido desenvolvidos instrumentos de avaliação que fornecem "feedback" acerca da qualidade/adequação dos cuidados prestados; aquisição de competências de autonomia nas diversas vertentes envolvidas numa existência que se quer independente; promoção da qualidade de vida; satisfação pelo trabalho ou qualquer outra forma de ocupação estruturada, ...

Paralelamente, as investigações desenvolvem-se e muito do que antes era afirmado empiricamente, é-o agora dito de forma sustentada e consistente. Ainda assim é necessário não esquecer que todos os estudos são muito úteis, mas não se podem enviesar respostas para se alcançarem os resultados esperados ou desejáveis. Sou apologista da investigação, mas não da "fabricação" de conclusões e de percentagens significativas e favoráveis ao que se quer comprovar. De tão exaustivo se querer ser, vai-se, por vezes, a um "detalhe impossível" e preenchem-se os quadros por aproximações resultantes das idiossincrasias dos investigadores. Ressalvo sempre que não podem fazer-se generalizações, pois, como todos sabemos, há investigações rigorosas que contribuem definitiva e verdadeiramente para a evolução, aperfeiçoamento e optimização das intervenções.

Ora, tudo isto nos faz pensar e é exactamente pela evolução que vai acontecendo, que consideramos essencial reflectir para além da realidade prática, mas com a percepção de quem se preocupa não apenas com o que se sabe, mas também com o que se sente e com o que as pessoas com doença mental integram na sua vida, no que se refere às suas emoções, aos seus sentimentos, aos seus objectivos e à sua forma de querer estar no mundo e na sociedade. 
Enfim, todo o trabalho que está a ser realizado é fundamental, mas não representa um pacote de soluções mágicas que serve de panaceia para todos os males. De facto, isto não existe e, se existisse, até ao dia em que o que é legalmente concebido estivesse condicente com as necessidades em termos de número de respostas, ainda haveria um longo caminho a percorrer.

Não podemos ignorar que algumas pessoas com doença mental (e isto tem a ver com as suas histórias e com os seus percursos desde o adoecimento) têm medo da comunidade e que outras têm medo da instituição e da hospitalização. É por isto que tem de haver lugar e respostas para todos.

\section{Há Tantas Doenças como Doentes}

Por mais longos que sejam já os nossos percursos a intervir junto de pessoas com doença mental, não deixaremos nunca de ser surpreendidos. A imprevisibilidade dos seus comportamentos, das suas atitudes, da forma de estabelecerem relações, ... é, apesar da nossa experiência, mesmo que vasta, algo que vai produzindo em nós menor dissonância, mas que não deixa de nos inquietar e de nos confrontar com situações face às quais nos sentimos impotentes na busca de melhores soluções.

Isto não quer, naturalmente, dizer que as pessoas com doença mental devam ser excluídas ou alvo de discriminação, mas sim que estas não se podem reduzir a um "manual de instruções" que inclua todas as suas características.

As manifestações do mesmo quadro diagnóstico podem ser diversas e é devido às idiossincrasias e ao enquadramento contextual de cada um que se diz que há tantas doenças mentais como doentes que delas são portadores.

\section{Malefícios da Institucionalização}

Apesar de a nossa experiência nos dizer que a desinstitucionalização ou a não institucionalização das pessoas com doença mental é a grande 
meta a alcançar e que só nos casos muito graves estas não devem ser equacionadas como uma resposta possível, há situações em que o internamento não pode ser evitado.

De qualquer forma devemos ter o maior cuidado para o prevenir, nunca permitindo que as respostas hospitalares sejam as mais disponíveis e as imediatamente equacionáveis. De facto, a institucionalização é, por si só, uma forma de adoecimento, pelo que se perde nesse meio que é "anti-natural" e que tudo permite em termos de comportamentos "marginais" e "marginalizantes".

No hospital psiquiátrico é possível deitar-se na relva quando se quer apanhar sol ou se quer descansar. Na comunidade não;

No hospital psiquiátrico é permitido andar de braguilha aberta. Na comunidade não;

No hospital psiquiátrico pode-se fazer chichi quando se tem vontade sem ir, necessariamente, à casa de banho. Na comunidade não.

Um dia alguém disse a propósito - "Aqui somos todos doidos e ninguém repara. Quando saio com os meus pais é que tenho de parecer normal, pois se o não fizer vão apontar-me o dedo e virar-me as costas porque sou louco."

No hospital perdem-se hábitos de estar bem socialmente e até se esquece o que isso é.

Claro que estamos a falar de um hospital psiquiátrico do antigamente e que, na actualidade, mesmo as instituições mais clássicas têm preocupações reabilitativas e de normalização contextual. Ainda assim, estas são, como já se disse, sempre que isso é possível, de evitar. É que a auto-imagem desvaloriza-se pela falta de exigência; o afastamento e a desresponsabilização da família (porque o doente "está entregue") são sempre promovidos; o "deixar de ser gente" é facilitado pela massificação das vivências e pelo paternalismo bem-intencionado de quem toma conta (os técnicos) e não quer que nada de mau aconteça; a cidadania "dilui-se" por não ter de ser vivida. 


\section{Reduzir Dependência/Promover Autonomia}

Reduzir a dependência e promover a autonomia das pessoas com doença mental é, antes de tudo, uma postura na relação com o doente e não tanto, apesar do que foi dito, uma implicação directa do contexto em que ele está inserido.

Este alerta, que parece contraditório, legitima-se no facto de que há muitas entidades que promovem o apoio na comunidade e cujos técnicos que nelas intervêm actuam como se as pessoas com doença mental fossem "tontos" apenas ávidos de carinho e de atenção e não merecessem um "olhar de igual" com o decorrente respeito pela sua existência, pela sua personalidade e pela sua história de vida que continua em edificação e não acabou com o emergir da patologia que lhe foi, a dada altura, diagnosticada.

Importa referir que intervir face à redução da dependência e à promoção da autonomia vai muito para além do que é desinstitucionalizar. Implica o controlo da doença e dos sintomas desta, mas também:

- Garantia de sobrevivência;

- Dignidade de habitação, de higiene e de cuidados pessoais;

- Realização através do trabalho/ ocupação;

- Prazer de viver;

- Estabelecimento de relações gratificantes; ...

Acima de tudo, não é possível ignorar que as pessoas com doença mental são muito mais do que a sua doença e que, na maioria (apesar de poderem precisar de apoio para gerirem a sua vontade), têm opinião e "nós" passamos a vida a dizer e a conceber o que é melhor para elas, a fazê-las concordar com isso e nem sequer lhes pedimos sugestões.

A vida afectiva, a dignidade, a vontade (ainda que, por vezes, comprometida) e a liberdade são bens inalienáveis pelos quais todos devemos lutar e pôr ao alcance daqueles com e para os quais trabalhamos, ainda que estes sejam pessoas com perturbações que temos dificuldade em 
conhecer na primeira pessoa porque nunca experimentámos essa forma de adoecer.

\section{Propostas para a Saúde Mental}

Tendo em conta todas as respostas que existem é fundamental vir ao encontro das reais necessidades das pessoas com doença mental em Portugal. As alternativas concebidas no âmbito dos cuidados continuados integrados de saúde mental são uma proposta clara e inequívoca, mas não são uma magia porque, como já se disse, não há soluções mágicas. Assim, é preciso perceber-se que:

- Os "números honestos" não podem construir-se a partir de "números escondidos";

- A desinstitucionalização não consiste em retirar doentes de um hospital psiquiátrico e integrá-los numa estrutura sobrelotada e sem condições;

- Os encerramentos de umas estruturas não podem fazer-se à custa de pressões para internamento noutras;

- Não podem, por noutro lado, haver instituições que existam e sobrevivam das desinstitucionalizações e encerramentos das que se comprometeram oficialmente a desaparecer;

- É preciso ser realista na identificação/avaliação de competências das pessoas com doença mental e na consciencialização das suas limitações;

- Nas instituições não pode haver serviços para doentes de $1 .^{\mathrm{a}}$, de 2. ${ }^{\mathrm{a}}$ e de $3 .^{\mathrm{a}}$;

- Os novos psicóticos com os quais, e bem, se utilizam todos os recursos disponíveis para evitar percursos dolorosos e institucionalizantes, não devem servir de pretexto para ignorar aqueles que há muito sofrem de uma patologia psiquiátrica grave e que, no seu tempo, apenas porque era assim, se viram confinados a viver "dentro de muros" e, alguns, ainda, "atrás de grades"; 


\section{Algumas Respostas Previstas na Legislação sobre os Cuidados Continuados Integrados de Saúde Mental}

A legislação sobre os Cuidados Continuados Integrados de Saúde Mental, ainda não regulamentada à data desta intervenção, concebe um conjunto de respostas complementares entre si, que visam abranger todas as pessoas com doença mental que carecem de acções especializadas. Estas são, sumariamente:

- Equipas de apoio domiciliário;

- Unidades sócio-ocupacionais;

- Unidades residenciais. Estas dividem-se em:

- Residências de Treino de Autonomia. A permanência dos residentes é até doze meses consecutivos. Têm uma lotação para seis a doze pessoas e podem albergar até seis utentes por estrutura modular;

- Residências Autónomas de Saúde Mental. Têm até sete lugares de capacidade máxima;

- Residências de Apoio Moderado. Têm seis a doze lugares e são concebidas com estruturas modulares de seis a oito residentes. Tal como as residências de apoio máximo a seguir referidas, prevêem dar resposta a situações de descanso das famílias (alívio programado) até trinta dias por ano;

- Residências de Apoio Máximo. Terão dezoito a trinta e dois lugares e as suas estruturas modulares integrarão seis a oito residentes.

\section{Problemas Previsivelmente Decorrentes}

Ao olharmos para esta síntese de respostas e ao concordarmos que nelas podem estar abrangidas as maiores necessidades das pessoas com doença mental em função do tipo e gravidade da sua doença, colocam-se-nos, no imediato, pelo menos duas grandes questões:

- Como reconverter as respostas institucionais que existem (com que meios?) se só as residências de treino de autonomia são preferen- 
cialmente na comunidade e as outras unidades são obrigatoriamente nesta? Vamos deitar muros abaixo para fazer de conta que não somos instituição? ... Se assim não for, onde iremos buscar os recursos necessários?

- Como formar/supervisionar os técnicos que trabalham já há algum tempo com pessoas com doença mental e têm conhecimentos, mas também hábitos institucionais, para que a comunidade não fique recheada de pequenas instituições psiquiátricas denominadas de residências? E se não forem estes que vão dar suporte às novas estruturas? Vamos "engordar" o número de desempregados com a desinstitucionalização de doentes mentais ou vamos "desempregar" os "antigos" para empregar "novos" e sem qualquer experiência?

\section{Reflexão Final Breve}

A intervenção que agora termino teve, como se pode constatar, o objectivo de, no contexto deste workshop, lançar pistas de reflexão e de discussão. De facto, estamos numa era em que o caminho feito na assistência a pessoas com doença mental (em tratamento e reabilitação) é irreversível e se distancia significativamente do que era concretizado num passado recente, mesmo quando se punham em prática as melhores respostas em cada momento.

Quando falo do passado e do presente em contraponto recordo uma história contada por Gabriel Garcia Marquez - Só Vim Fazer um Telefonema - integrada numa colectânea que dá pelo nome "Doze Contos Peregrinos". Sem querer perder-me nela, a narrativa descreve uma situação vivida por uma mulher que, ao pé da cidade de Barcelona, em 1978, junto ao carro avariado numa noite de temporal, pede boleia para chegar a um qualquer lugar onde a deixem telefonar para o marido/companheiro. É acolhida num mini autocarro que transporta outras mulheres que residiam num hospital psiquiátrico e que, nesse dia, tinham ido dar um passeio. Depois de várias situações vividas e tentativas de se fazer entender, ninguém a compreende, ninguém a ouve, o marido convence- 
-se que está mesmo perturbada e a sua vida, ali interrompida, passa a ser integrada num "manicómio".

Todos sabemos que actualmente isto nunca poderia acontecer, mas histórias destas fazem-nos pensar o que pode custar a alguém não chegar a ser ouvido.

Visto que não existem soluções mágicas nem doentes triados pertencentes a elites pré definidas em função de requisitos desejáveis, há que ter presente que a realidade das pessoas com doença mental é, apesar de tudo e de todos os avanços legais e científicos, muito dura ainda, e não será fácil que, um dia, deixe de o ser. No entanto, uma coisa era enfrentar dificuldades sem vislumbre de solução; outra é confrontar-se com elas com motivos de esperança e perspectivas de um amanhã melhor. Podemos considerar que, em 2009, é deste modo que estamos a viver e a intervir.

Prossigamos um caminho atento e respeitemos os que de nós precisam, investindo plenamente sem temer qualquer insucesso ou frustração, nem que seja porque sabemos estar a fazer o melhor que é possível.

\section{Referências bibliográficas}

Assalian, P., Fraser, R., Tempier, R. \& COHEN, D. (2000). "Sexuality and Quality of Life of Patients with Schizophrenia”. International Journal of Psychiatry in Clinical Practice, Vol. 4, 29-33.

Abreu, M. V. \& SAntos, E. R. (2008). O Papel das Famílias e das Redes de Apoio Social Actas do I Congresso de Reabilitação e Inclusão em Saúde Mental. Coimbra: Almedina Editora.

Decreto-Lei $n .^{\circ}$ 281/2003 de 8 de Novembro.

Decreto-Lei n. ${ }^{\circ}$ 507/2009 de 9 de Setembro.

LEFF, J. (2000). Cuidados na Comunidade - Ilusão ou Realidade? Lisboa: Climepsi Ed. LOPEZ, S. (2008). O Solista. Estrelapolar.

MARqueZ, G. G. (1995). Doze Contos Peregrinos. Lisboa: Publicações Dom Quixote.

Reestruturação e Desenvolvimento dos Serviços de Saúde Mental em Portugal, Plano de Acção 2007-2016.

Saúde Mental, Antologia de Textos para Utentes e Familiares, FNAFSAM, Lisboa, 2007.

Tempos e Modos - III Jornadas de Reabilitação Psicossocial da Casa de Saúde do Telhal, Edição da Casa de Saúde do Telhal, 2007. 